\title{
Gold as a 6p-element in Dense Lithium Aurides
}

Guochun Yang ${ }^{1,2}$, Yanchao Wang ${ }^{1}$, Feng Peng ${ }^{1}$, Aitor Bergara ${ }^{3,4,5}$, and Yanming $\mathrm{Ma}^{1, *}$

${ }^{1}$ State Key Laboratory of Superhard Materials, Jilin University, Changchun 130012, China.

${ }^{2}$ Faculty of Chemistry, Northeast Normal University, Changchun 130024, China.

${ }^{3}$ Depto. de Física de la Materia Condensada, Universidad del País Vasco, UPV/EHU, 48080 Bilbao, Spain

${ }^{4}$ Donostia International Physics Center (DIPC), 20018 Donostia, Spain

${ }^{5}$ Centro de Física de Materiales CFM, Centro Mixto CSIC-UPV/EHU, 20018

Donostia, Spain 
1. Computational details

2. Validity test of projected density of states (PDOS) S5

3. Calculated lattice parameters and atomic positions of stable $\mathrm{Li}-\mathrm{Au}$ compounds S6

4. Phase stabilities of various $\mathrm{Li}_{n} \mathrm{Au}_{m}$ compounds at 500 and $1000 \mathrm{~K} \cdots \cdots \cdots \cdots \cdots \cdot \mathrm{S} 8$

5. Shortest $\mathrm{Li}-\mathrm{Li}, \mathrm{Li}-\mathrm{Au}$, and $\mathrm{Au}-\mathrm{Au}$ distances at $50 \mathrm{GPa}$ in $\mathrm{Li}_{n} \mathrm{Au}(n=1-5) \cdots \cdots \cdot \mathrm{S} 9$

6. The most stable structures of $\mathrm{Li}_{n} \mathrm{Au}(n=1-6)$ at $100 \mathrm{GPa} \cdots \cdots \cdots \cdots \cdots \cdots \cdot \cdots \cdot \cdots \cdot \mathrm{S} 10$

7. The Shortest Li-Li, Li-Au, and $\mathrm{Au}-\mathrm{Au}$ distances in $\mathrm{Li}_{n} \mathrm{Au}(n=1-4)$ at $25 \mathrm{GP} \cdots \mathrm{S} 11$

8. The Shortest $\mathrm{Li}-\mathrm{Li}, \mathrm{Li}-\mathrm{Au}$, and $\mathrm{Au}-\mathrm{Au}$ distances in $\mathrm{Li}_{n} \mathrm{Au}(n=1-6)$ at 100 $\mathrm{GPa}$

9. Crystal structure of $\mathrm{LiAu}_{2}$ with $I 4 / \mathrm{mmm}$ symmetry at $50 \mathrm{GPa} \cdots \cdots \cdots \cdots \cdots \cdots \cdots \cdot \mathrm{S} 12$

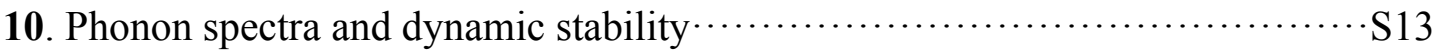

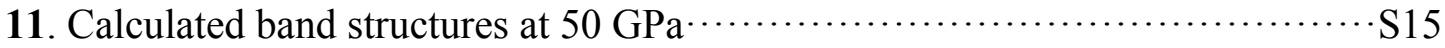

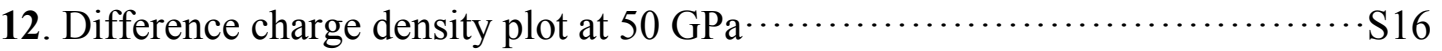

13. The calculated projected density of states per atom (PDOS) $\cdots \cdots \cdots \cdots \cdots \cdots \cdots \cdots \cdot \mathrm{S} 17$

14. Comparison of projected density of states per atom (PDOS) of Au $6 s$ state $\cdots \cdot \mathrm{S} 18$

15. Projected density of states per atom (PDOS) of $\mathrm{Au} 5 d$ states for $\mathrm{Li}_{n} \mathrm{Au}(n=1-5)$ at $50 \mathrm{GPa}$

16. Projected density of states (PDOS) of $\mathrm{Li}_{3} \mathrm{Au}$ at $0 \mathrm{GPa}$ S20

17. Comparison of projected density of states per atom (PDOS) of $\mathrm{Au} 6 s$ for $\mathrm{Li}_{3} \mathrm{Au}$, $\mathrm{Li}_{4} \mathrm{Au}, \mathrm{Li}_{5} \mathrm{Au}$, and $\mathrm{CsAu}$ S2 1

18. Main results of Cs-Au compounds S22

19. Atomic orbital energy levels for $\mathrm{Cs}$ and $\mathrm{Au}$ atoms under pressures S23

20. References 


\section{Computational Details}

Our structural prediction approach is based on a global minimization of free energy surfaces merging ab initio total-energy calculations with CALYPSO (Crystal structure AnaLYsis by Particle Swarm Optimization) methodology as implemented in the CALYPSO code. ${ }^{1,2}$ The structures of stoichiometry $\operatorname{Li}_{n} \mathrm{Au}_{m}(n=1-6$ and $m=1$, or $n=$ 1 and $m=1-6)$ were searched with simulation cell sizes of 1-4 formula units (f.u.) at 0 , 25, 50, and $100 \mathrm{GPa}$. In the first step, random structures with certain symmetry are constructed in which atomic coordinates are generated by the crystallographic symmetry operations. Local optimizations using the VASP $\operatorname{code}^{3}$ were done with the conjugate gradients method and stopped when Gibbs free energy changes became smaller than $1 \times 10^{-5} \mathrm{eV}$ per cell. After processing the first generation structures, $60 \%$ of them with lower Gibbs free energies are selected to construct the next generation structures by PSO (Particle Swarm Optimization). $40 \%$ of the structures in the new generation are randomly generated. A structure fingerprinting technique of bond characterization matrix is applied to the generated structures, so that identical structures are strictly forbidden. These procedures significantly enhance the diversity of the structures, which is crucial for structural global search efficiency. In most cases, structural searching simulations for each calculation were stopped after generating $1000 \sim 1200$ structures (e.g., about $20 \sim 30$ generations).

To further analyze the structures with higher accuracy, we select a number of structures with lower Gibbs free energies and perform structural optimization using density functional theory within the generalized gradient approximation ${ }^{4}$ as implemented in the VASP code. The cut-off energy for the expansion of wavefunctions into plane waves is set to $700 \mathrm{eV}$ in all calculations, and the Monkhorst-Pack $k$-mesh with a maximum spacing of $0.02 \AA^{-1}$ was individually adjusted in reciprocal space with respect to the size of each computational cell. This usually gives total energies well converged within $\sim 1 \mathrm{meV} /$ atom. Electron-ion interactions were described within the projector augmented wave method with $s^{1} p^{0}$ and $5 d^{10} 6 s^{1}$ orbitals as valence states for Li and Au atoms, respectively. 
With the only input of chemical compositions in our CALYPSO structure searching calculations, the experimental $\mathrm{Cu}_{3} \mathrm{Al}$-type structure of $\mathrm{Li}_{3} \mathrm{Au}$ (space group $\mathrm{Fm}-3 m, 4$ formula unit per cell) $)^{5}$ were successfully reproduced at $0 \mathrm{GPa}$, validating our structure searching methodology in application to Li-Au system. Moreover, the relaxed lattice constant for $\mathrm{Cu}_{3} \mathrm{Al}$-type structure of $\mathrm{Li}_{3} \mathrm{Au}$ was calculated to be $6.31 \AA$, in good agreement with the experimental value of $6.30 \AA^{5} .^{5}$ These lattice parameter calculations gave support to the validity of pseudopotentials adopted in this work.

To investigate the relative strength of the chemical bonding between $\mathrm{Li}-\mathrm{Li}, \mathrm{Li}-\mathrm{Au}$, and $\mathrm{Au}-\mathrm{Au}$, tight-binding electronic structure calculations were performed for $\mathrm{Li}_{n} \mathrm{Au}$ compounds according to the linear-muffin-tin-orbital (LMTO) method in the atomic sphere approximation (ASA). ${ }^{6}$ The radii of the Wigner-Seitz (WS) spheres were assigned automatically so that the overlapping potentials would be the best possible approximations to the full potentials. ${ }^{7}$ For bonding analysis, the energy contributions of filled electronic states for all $\mathrm{Li}-\mathrm{Li}, \mathrm{Li}-\mathrm{Au}$, and $\mathrm{Au}-\mathrm{Au}$ contacts were calculated as functions of the energy according to the crystal orbital Hamilton population (COHP) method. ${ }^{8}$ Weighted integration of COHP data for each bond type over all filled states yielded ICOHP, the Hamilton overlap populations. To assess the phase stability of the studied Li-Au compounds, the quasi-harmonic model ${ }^{9}$ was adopted to calculate the phonon spectra using the supercell method. The ELF was also calculated using VASP. 


\section{Validity Test of Projected Density of States (PDOS) and Pseudopotentials}
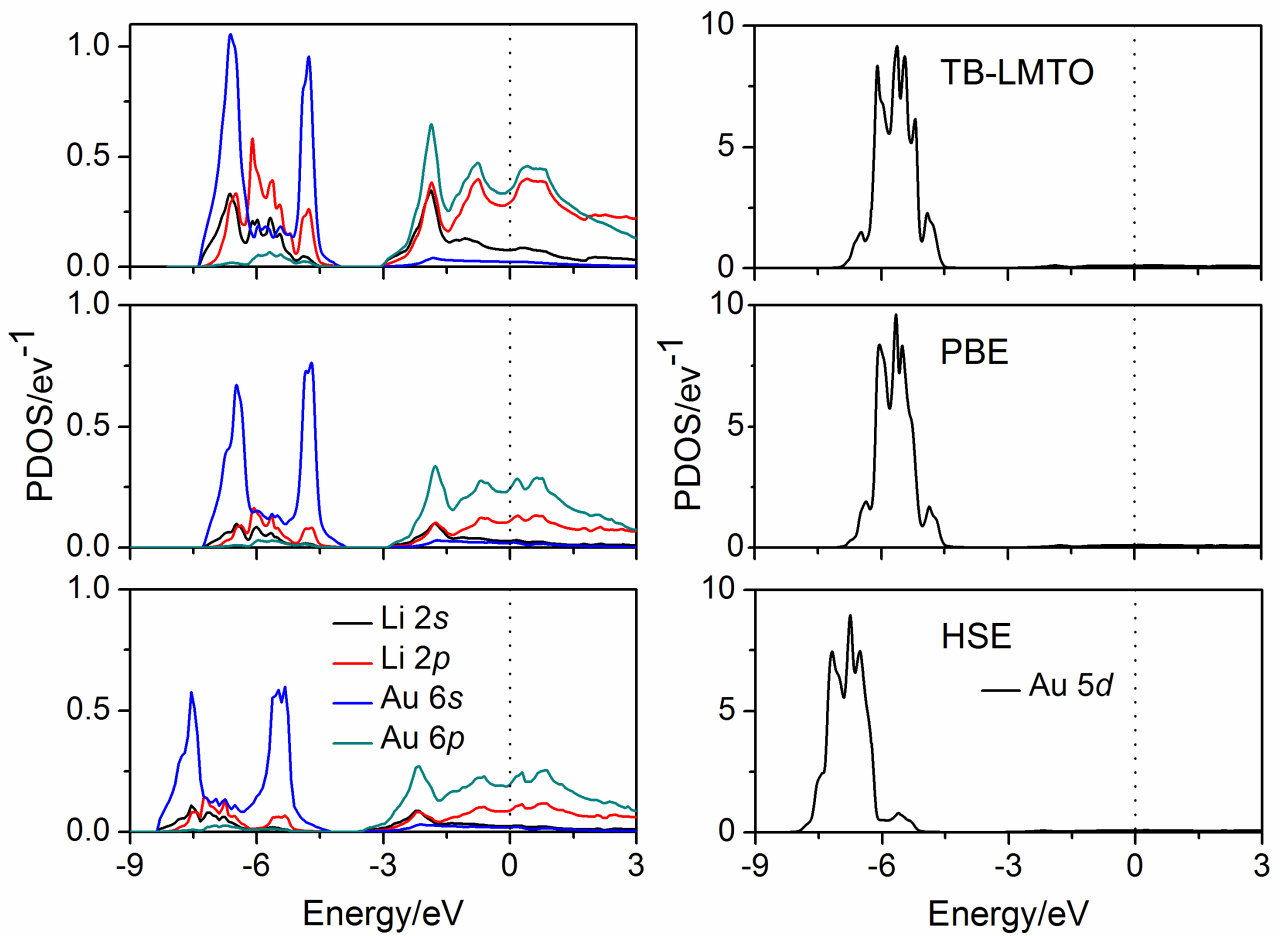

Figure S0a. Projected density of states (PDOS) of $\mathrm{Li}_{4} \mathrm{Au}$ under $50 \mathrm{GPa}$ calculated by the tight-binding linear muffin-tin orbital (LMTO), Perdew-Burke-Ernzerh (PBE) functional, and Heyd-Scuseria-Ernzerhof (HSE) hybrid functional. These methods show similar major features, not only the line shapes but also the energy positions. It is noted that the overlap of the Au $6 p$ states and Li $2 p$ ones near the Fermi energy were well reproduced by these methods. The PDOS intensities obtained from LMTO are slightly larger than those of PBE and HSE, which result from the use of different size of the spheres where PDOS are projected. The TB-LMTO implements atomic spheres approximation (ASA) and uses significantly larger spheres for each element. In this paper, we use the results coming from the PBE functional. 


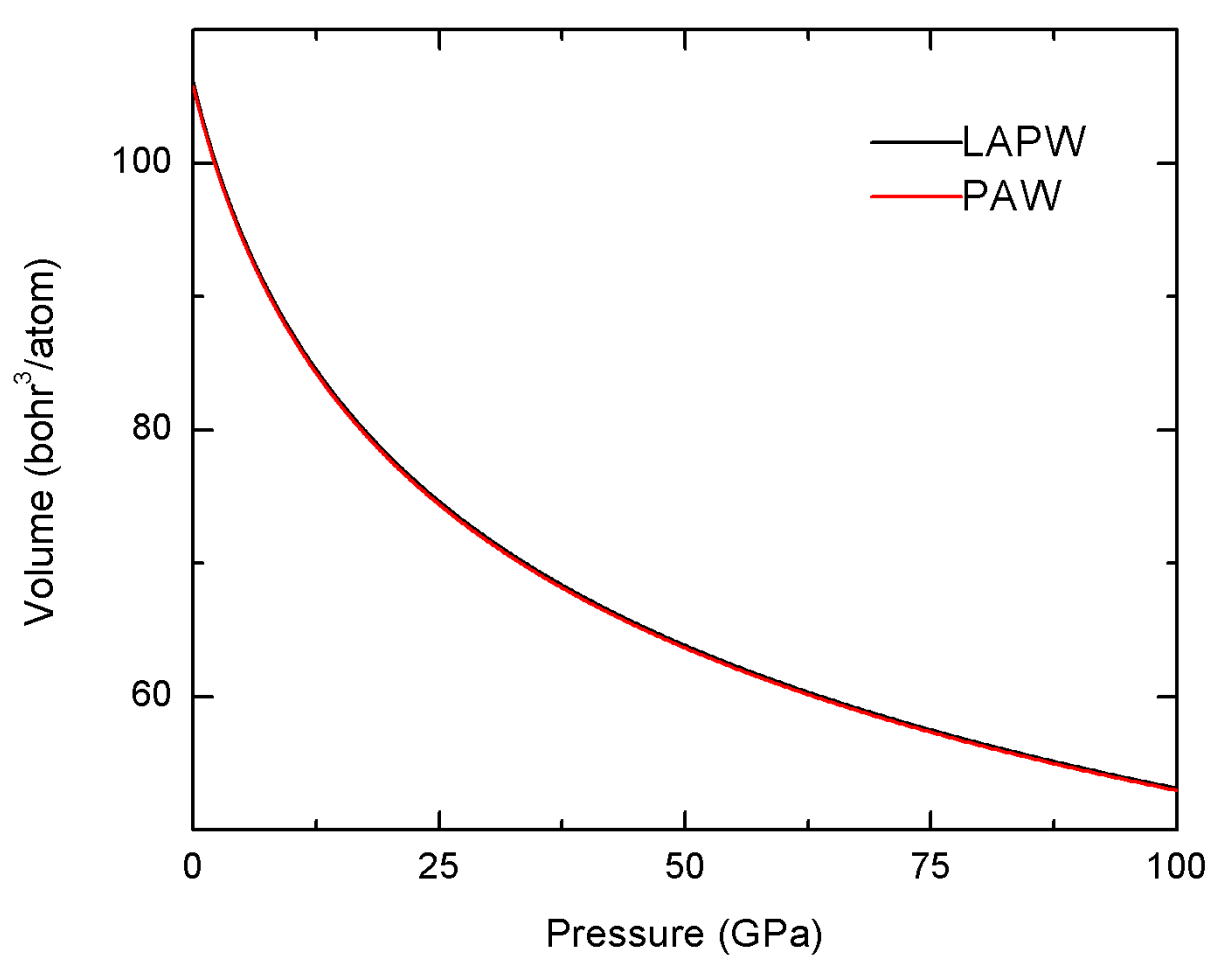

Figure S0b. Comparison of the fitted Birch-Murnaghan equation of state for $\mathrm{Li}_{3} \mathrm{Au}$ in the Fm-3m structure by using PAW pseudopotential and the full-potential LAPW method. The result indicates that the PAW potentials are applicable to $\mathrm{Li}-\mathrm{Au}$ compounds under high pressure.

\section{Structural Parameters}

Table S1. The calculated lattice parameters (in Angstroms) and atomic positions for the selected stable $\mathrm{Li}_{n} \mathrm{Au}_{m}$ structures. 


\begin{tabular}{|c|c|c|c|c|c|c|c|c|}
\hline & Space group & $\begin{array}{c}\text { Pressure } \\
\text { (Range) }\end{array}$ & $\begin{array}{c}\text { Lattice } \\
\text { parameters }\end{array}$ & Atom & Site & & mic positi & \\
\hline \multirow[t]{3}{*}{$\mathrm{Li}_{6} \mathrm{Au}$} & $\mathrm{Immm}$ & $100 \mathrm{GPa}$ & $a=3.4793$ & $\mathrm{Li}$ & $8 \mathrm{i}$ & 0.00000 & 0.72697 & 0.14299 \\
\hline & & & $b=4.6263$ & $\mathrm{Li}$ & $4 i$ & 0.00000 & 0.00000 & 0.34626 \\
\hline & & & $c=6.0249$ & $\mathrm{Au}$ & $2 b$ & 0.50000 & 0.00000 & 0.00000 \\
\hline \multirow[t]{10}{*}{$\mathrm{Li}_{5} \mathrm{Au}$} & $C 2 / m$ & $100 \mathrm{GPa}$ & $a=6.9702$ & $\mathrm{Li}$ & $8 \mathrm{j}$ & 0.25384 & 0.25418 & 0.00018 \\
\hline & & & $b=4.4231$ & $\mathrm{Li}$ & $8 \mathrm{j}$ & 0.36698 & 0.14603 & 0.55924 \\
\hline & & & $c=10.3507$ & $\mathrm{Li}$ & $8 j$ & 0.85282 & 0.63158 & 0.55954 \\
\hline & & & $\beta=147.99$ & $\mathrm{Li}$ & $8 \mathrm{j}$ & 0.31256 & 0.68792 & 0.21542 \\
\hline & & & & $\mathrm{Au}$ & $8 \mathrm{j}$ & 0.29795 & 0.70213 & 0.80802 \\
\hline & & & & $\mathrm{Au}$ & $8 \mathrm{j}$ & 0.70205 & 0.29787 & 0.19198 \\
\hline & $\mathrm{Cmcm}$ & $50 \mathrm{GPa}$ & $a=3.7134$ & $\mathrm{Li}$ & $8 \mathrm{f}$ & 0.00000 & 0.15172 & 0.04487 \\
\hline & & & $b=7.9533$ & $\mathrm{Li}$ & $4 c$ & 0.00000 & 0.98704 & 0.25000 \\
\hline & & & $c=7.1813$ & $\mathrm{Li}$ & $8 \mathrm{f}$ & 0.50000 & 0.10099 & 0.89619 \\
\hline & & & & $\mathrm{Au}$ & $4 c$ & 0.50000 & 0.80797 & 0.75000 \\
\hline \multirow[t]{5}{*}{$\mathrm{Li}_{4} \mathrm{Au}$} & $I 4 / \mathrm{mmm}$ & $100 \mathrm{GPa}$ & $a=3.1265$ & $\mathrm{Li}$ & $4 e$ & 0.50000 & 0.50000 & 0.38317 \\
\hline & & & $c=7.3038$ & $\mathrm{Li}$ & $4 d$ & 0.50000 & 0.00000 & 0.25000 \\
\hline & & & & $\mathrm{Au}$ & $2 b$ & 0.00000 & 0.00000 & 0.50000 \\
\hline & $I 4 / m$ & $50 \mathrm{GPa}$ & $a=4.8608$ & $\mathrm{Li}$ & $8 \mathrm{~h}$ & 0.20178 & 0.44057 & 0.00000 \\
\hline & & $(25-50 \mathrm{GPa})$ & $c=3.8411$ & $\mathrm{Au}$ & $2 a$ & 0.00000 & 0.00000 & 0.00000 \\
\hline \multirow[t]{6}{*}{$\mathrm{Li}_{3} \mathrm{Au}$} & $\mathrm{Cmcm}$ & $100 \mathrm{GPa}$ & $a=3.4682$ & $\mathrm{Li}$ & $8 \mathrm{f}$ & 0.00000 & 0.88059 & 0.55214 \\
\hline & & & $b=7.5469$ & $\mathrm{Li}$ & $4 c$ & 0.00000 & 0.70666 & 0.25000 \\
\hline & & & $c=4.6646$ & $\mathrm{Au}$ & $4 c$ & 0.50000 & 0.08914 & 0.75000 \\
\hline & $F m-3 m$ & $50 \mathrm{GPa}$ & $a=5.3291$ & $\mathrm{Li}$ & $4 \mathrm{~b}$ & 0.00000 & 0.00000 & 0.50000 \\
\hline & & $(0-50 \mathrm{GPa})$ & & $\mathrm{Li}$ & $8 \mathrm{c}$ & 0.75000 & 0.25000 & 0.75000 \\
\hline & & & & $\mathrm{Au}$ & $4 a$ & 0.00000 & 0.00000 & 0.00000 \\
\hline \multirow[t]{9}{*}{$\mathrm{Li}_{2} \mathrm{Au}$} & Imma & $100 \mathrm{GPa}$ & $a=3.2316$ & $\mathrm{Li}$ & $16 \mathrm{j}$ & 0.75000 & 0.08647 & 0.19406 \\
\hline & & & $b=5.7210$ & $\mathrm{Au}$ & $4 e$ & 0.25000 & 0.30257 & 0.00000 \\
\hline & & & $c=5.2806$ & & & & & \\
\hline & $P 6 / \mathrm{mmm}$ & $50 \mathrm{GPa}$ & $a=3.5893$ & $\mathrm{Li}$ & 61 & 0.66667 & 0.33333 & 0.00000 \\
\hline & & (25GPa) & $c=2.6388$ & $\mathrm{Au}$ & $1 b$ & 0.00000 & 0.00000 & 0.50000 \\
\hline & & & $\gamma=120.00$ & & & & & \\
\hline & Immm & $0 \mathrm{GPa}$ & $a=2.8394$ & $\mathrm{Li}$ & $4 j$ & 0.00000 & 0.50000 & 0.65936 \\
\hline & & & $b=3.9912$ & $\mathrm{Au}$ & $2 d$ & 0.00000 & 0.50000 & 0.00000 \\
\hline & & & $c=8.2820$ & & & & & \\
\hline \multirow[t]{2}{*}{$\mathrm{LiAu}$} & $P m-3 m$ & $50 \mathrm{GPa}$ & $a=2.7875$ & $\mathrm{Li}$ & $1 b$ & 0.50000 & 0.50000 & 0.50000 \\
\hline & & $(0-100 \mathrm{GPa})$ & & $\mathrm{Au}$ & $1 \mathrm{a}$ & 0.00000 & 0.00000 & 0.00000 \\
\hline \multirow[t]{2}{*}{$\mathrm{LiAu}_{2}$} & $14 / \mathrm{mmm}$ & $100 \mathrm{GPa}$ & $a=2.6398$ & $\mathrm{Li}$ & $2 a$ & 0.00000 & 0.00000 & 0.00000 \\
\hline & & (50-100GPa) & $c=9.2550$ & $\mathrm{Au}$ & $4 \mathrm{e}$ & 0.00000 & 0.00000 & 0.64433 \\
\hline \multirow[t]{2}{*}{$\mathrm{LiAu}_{3}$} & $P m-3 m$ & $0 \mathrm{GPa}$ & $a=4.0761$ & $\mathrm{Li}$ & $1 b$ & 0.50000 & 0.50000 & 0.50000 \\
\hline & & $(0-25 \mathrm{GPa})$ & & $\mathrm{Au}$ & $3 c$ & 0.00000 & 0.50000 & 0.00000 \\
\hline
\end{tabular}



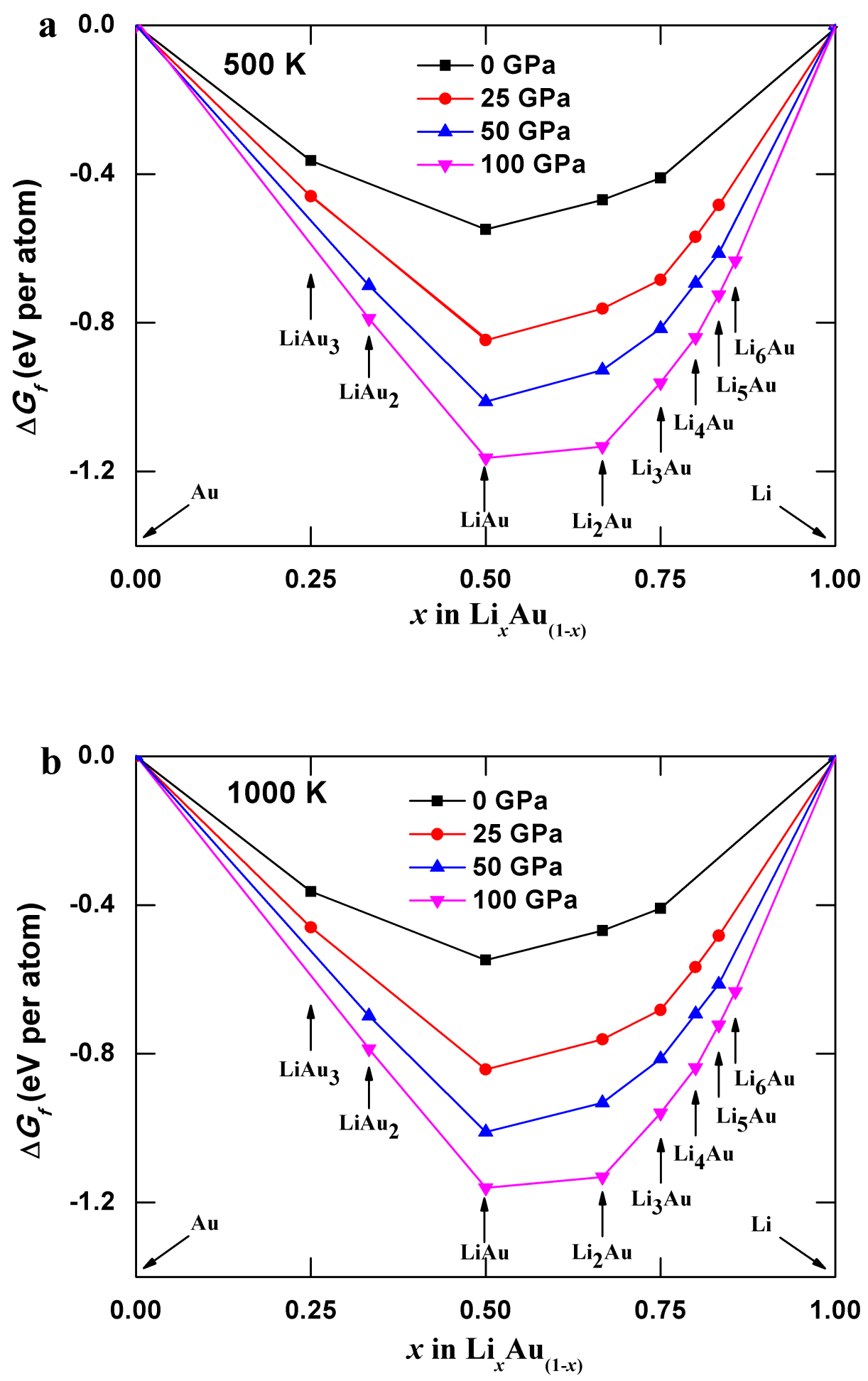

Figure S1. Phase stabilities of various $\mathrm{Li}_{n} \mathrm{Au}_{m}$ compounds at 500 (a) and 1000 (b) K. Here, only stable stoichiometries at $0 \mathrm{~K}$ are considered. ${ }^{10}$ 


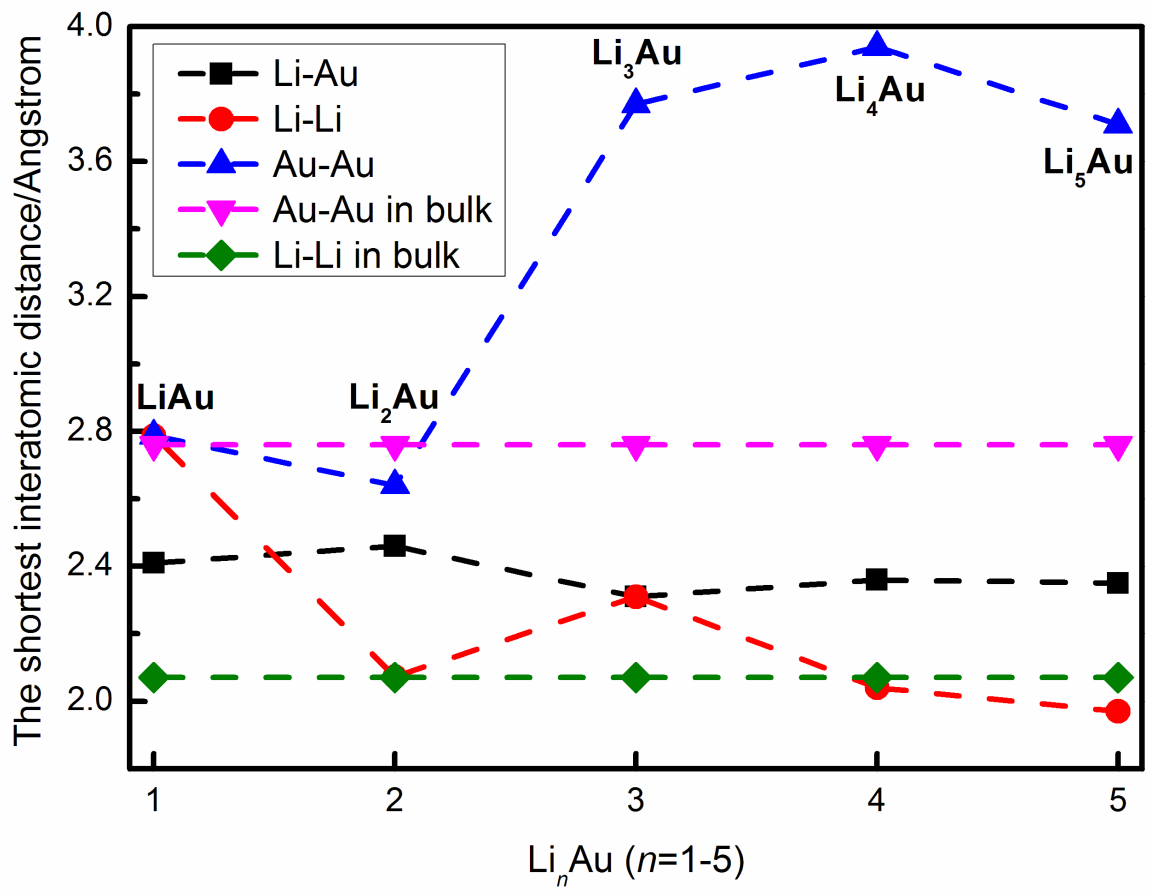

Figure S2. The shortest $\mathrm{Li}-\mathrm{Li}, \mathrm{Li}-\mathrm{Au}$, and $\mathrm{Au}-\mathrm{Au}$ distances in $\mathrm{Li}_{n} \mathrm{Au}(n=1-5)$ at 50 GPa. $\mathrm{Li}-\mathrm{Li}$ and $\mathrm{Au}-\mathrm{Au}$ distances corresponding to bulk materials at $50 \mathrm{GPa}$ are also included. With increasing Li-composition, Au-Au distances become much longer than in bulk materials. 


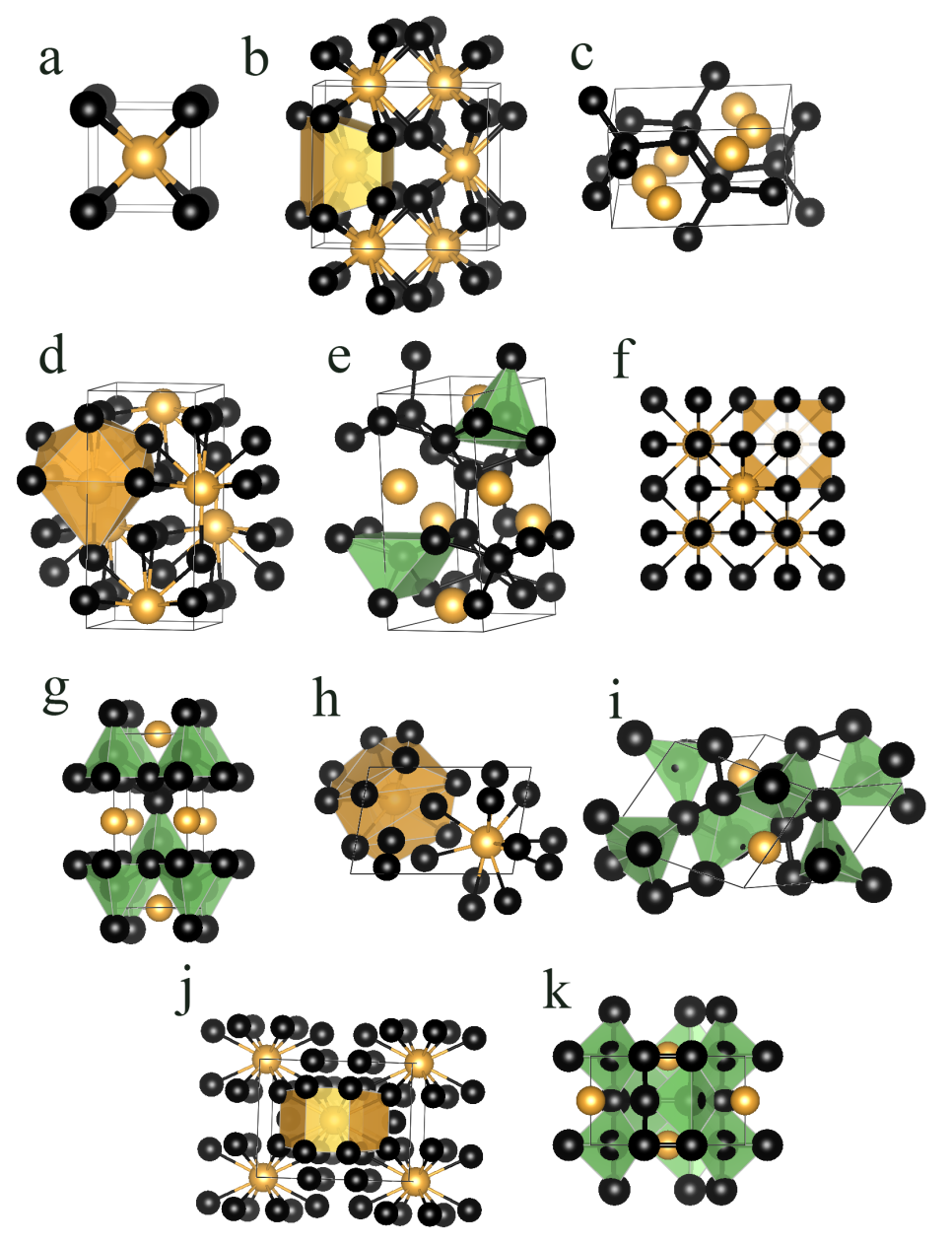

Figure S3. The most stable structures of $\mathrm{Li}_{n} \mathrm{Au}(n=1-6)$ at $100 \mathrm{GPa}$. (The parameters of all the structures are listed in Table S1). (a) LiAu in the Pm-3m structure. (b) $\mathrm{Li}_{2} \mathrm{Au}$ in the Imma structure. (c) The network structure in the Imma structure of $\mathrm{Li}_{2} \mathrm{Au}$. (d) $\mathrm{Li}_{3} \mathrm{Au}$ in the $\mathrm{Cmcm}$ structure. (e). Li cluster structure in the Cmcm structure of $\mathrm{Li}_{3} \mathrm{Au}$. (f) $\mathrm{Li}_{4} \mathrm{Au}$ in the $I 4 / m m m$ structure. (g) Li cluster structure in the $I 4 / m m m$ structure of $\mathrm{Li}_{4} \mathrm{Au}$. (h) $\mathrm{Li}_{5} \mathrm{Au}$ in the $C 2 / m$ structure. (i) $\mathrm{Li}$ cluster structure in the $C 2 / m$ structure of $\mathrm{Li}_{5} \mathrm{Au}$. (j) $\mathrm{Li}_{6} \mathrm{Au}$ in the Imma structure. (k) Li cluster structure in the Imma structure of $\mathrm{Li}_{6} \mathrm{Au}$. In all the structures, the small black and large yellow balls represent $\mathrm{Li}$ and $\mathrm{Au}$ atoms, respectively. These compounds favor the formation of Au-centered Au-Li polyhedrons. The clustering of Li atoms is also observed and is similar to what is observed in Li-Cs compounds under high pressure. ${ }^{11}$ Distances of nearest neighboring $\mathrm{Au}$ atoms also increase with increasing the Li-composition. 


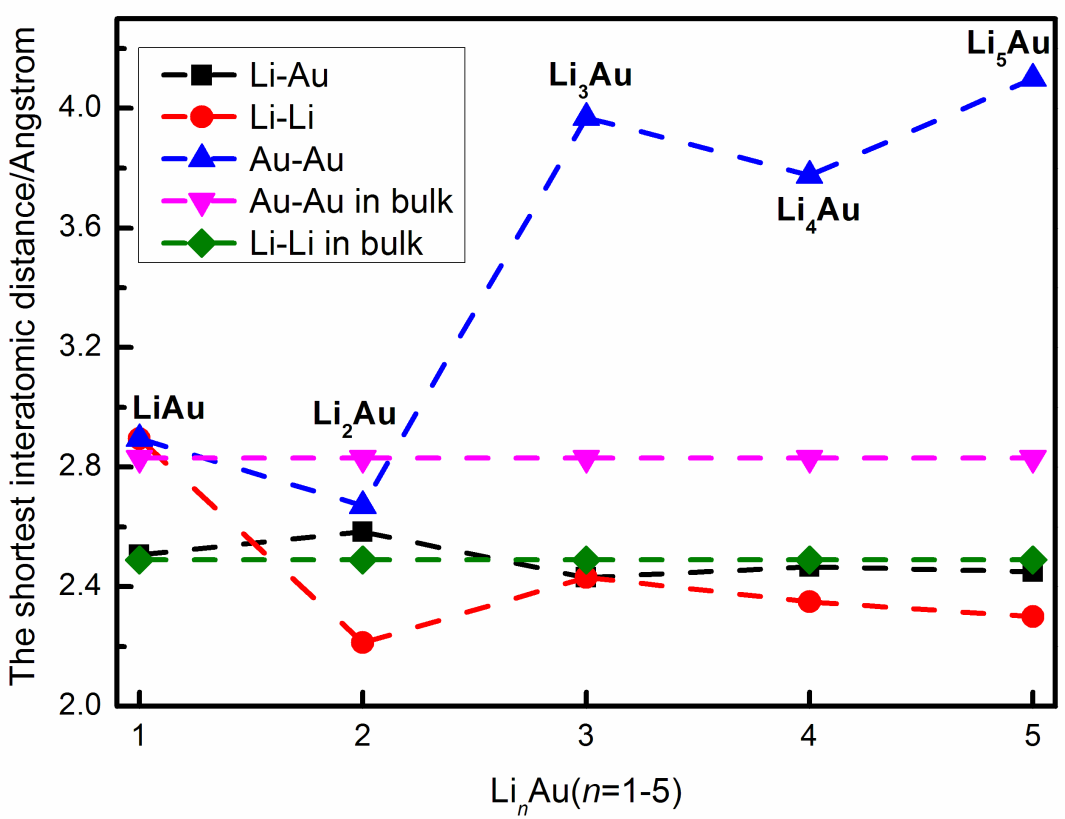

Figure S4. The shortest $\mathrm{Li}-\mathrm{Li}, \mathrm{Li}-\mathrm{Au}$, and $\mathrm{Au}-\mathrm{Au}$ distances in $\mathrm{Li}_{n} \mathrm{Au}(n=1-5)$ at 25 GPa. $\mathrm{Li}-\mathrm{Li}$ and $\mathrm{Au}-\mathrm{Au}$ distances corresponding to bulk materials at $25 \mathrm{GPa}$ are also included. With increasing the Li-composition, $\mathrm{Au}-\mathrm{Au}$ distances become much longer than in bulk.

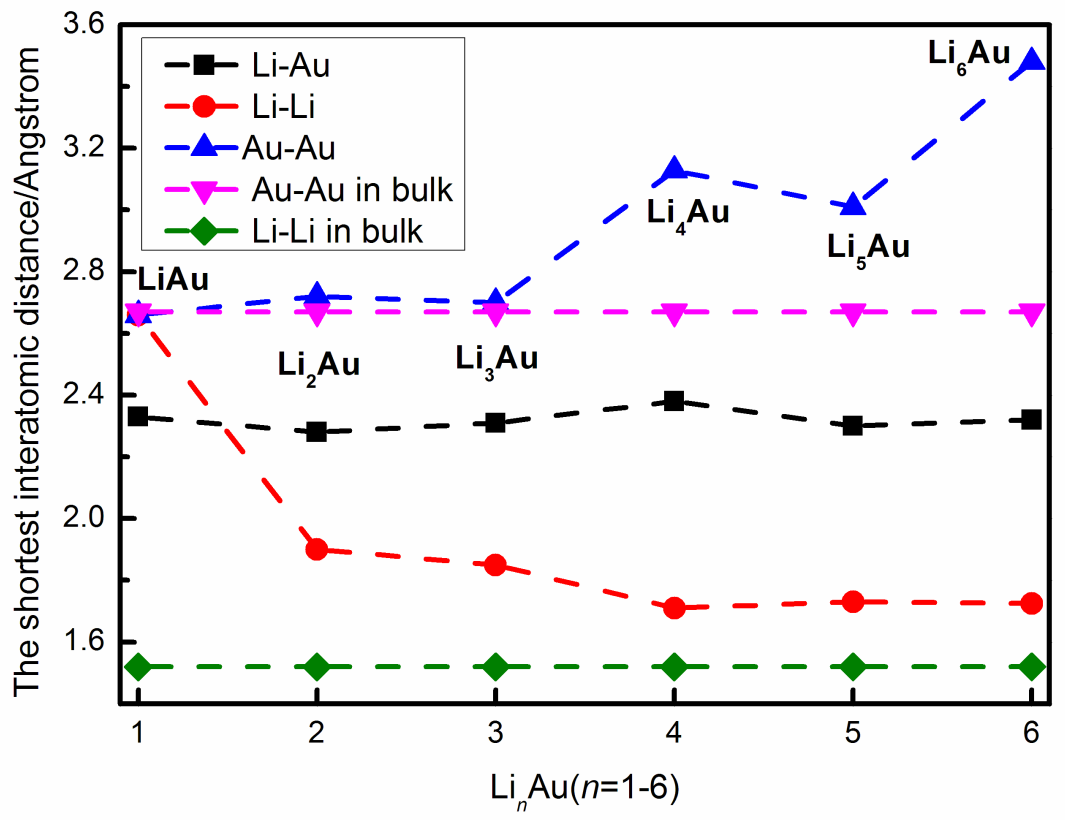

Figure S5. The shortest $\mathrm{Li}-\mathrm{Li}, \mathrm{Li}-\mathrm{Au}$, and $\mathrm{Au}-\mathrm{Au}$ distances in $\mathrm{Li}_{n} \mathrm{Au}(n=1-6)$ at 100 GPa. Li-Li and Au-Au distances corresponding to bulk materials are also included at $100 \mathrm{GPa}$. With increasing Li-composition, Au-Au distances become much longer than that in bulk. 

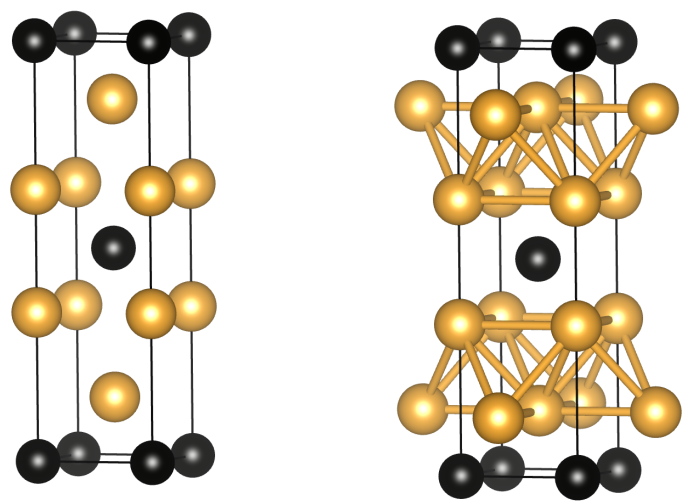

Figure S6. The stable structure of $\mathrm{LiAu}_{2}$ at $50 \mathrm{GPa}$ with $\mathrm{I} / \mathrm{mmm}$ symmetry consists of a stacking sequence of AuAuLiAuAuLi (left). The nearest $\mathrm{Au}$ atoms form $\mathrm{Au}$ clusters with Au-Au distance of $2.79 \AA$ (right), which is nearly equal to bulk Au at 50 GPa. 


\section{Phonon Spectra and Dynamic Stability}

In order to check the dynamic stability of the studied preferred structures, we have calculated their phonon spectra in a pressure ranging from $0 \mathrm{GPa}$ to $100 \mathrm{GPa}$. We found that there are no imaginary modes for these structures in their stability pressure range. To simplify, we just show the phonon dispersion of the three most important structures at $50 \mathrm{GPa}$.
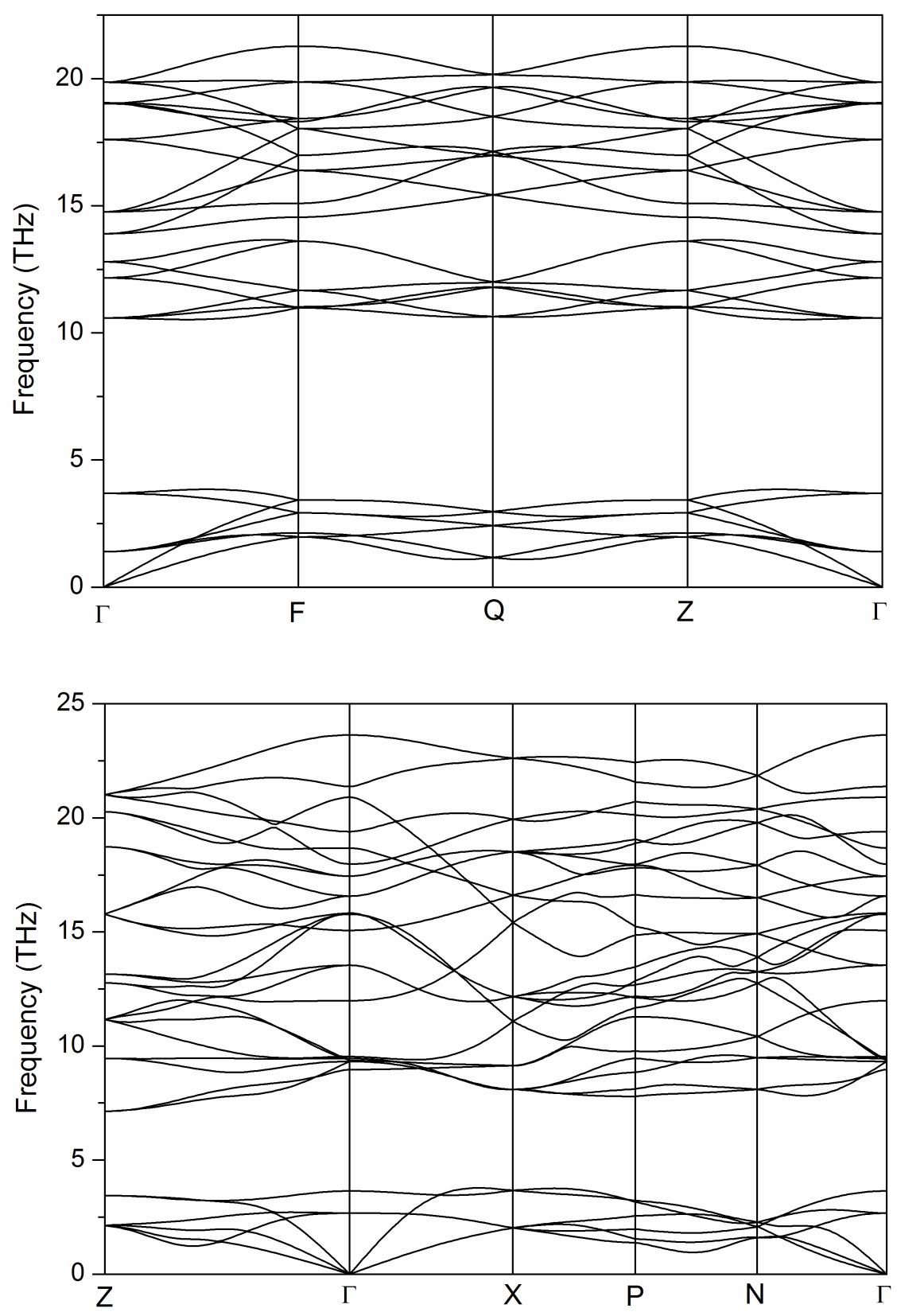


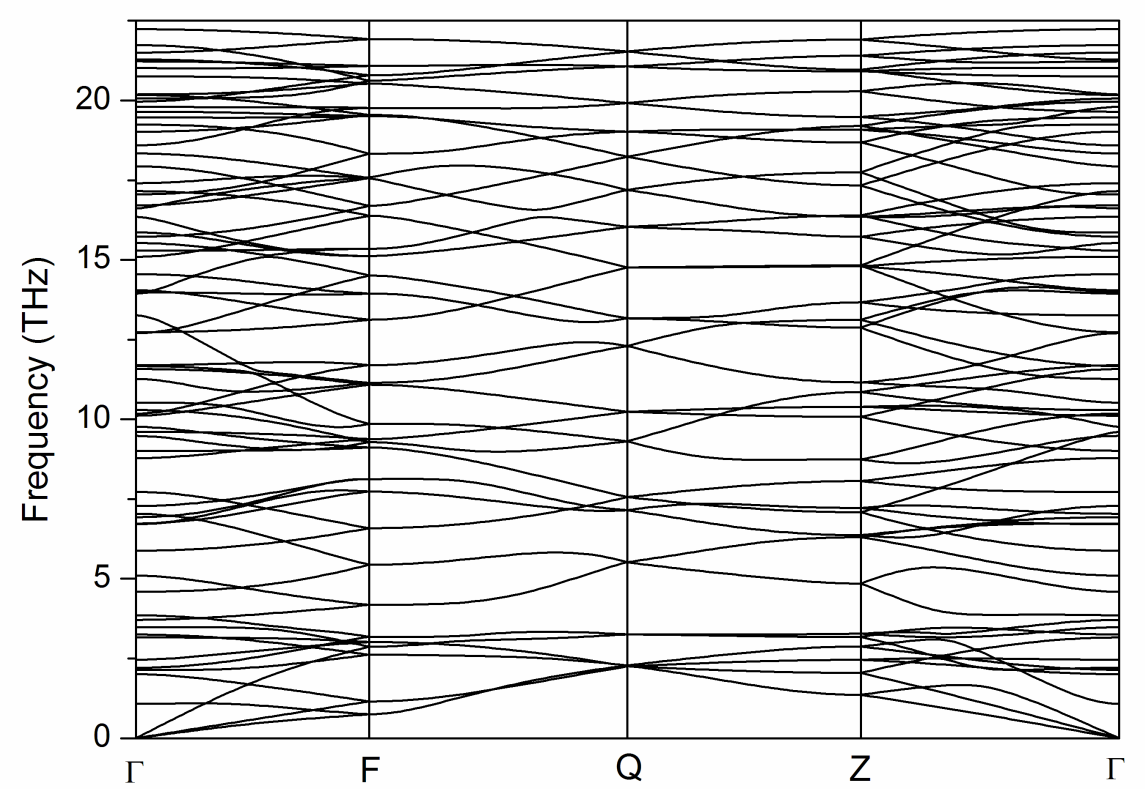

Figure S7. From top to bottom: phonon spectra of $\mathrm{Li}_{3} \mathrm{Au}$ in the $\mathrm{Fm}-3 m$ structure, $\mathrm{Li}_{4} \mathrm{Au}$ in the $I 4 / \mathrm{m}$ structure, and $\mathrm{Li}_{5} \mathrm{Au}$ in the $\mathrm{Cmmm}$ structure at $50 \mathrm{GPa}$. 
5. Electronic Structure
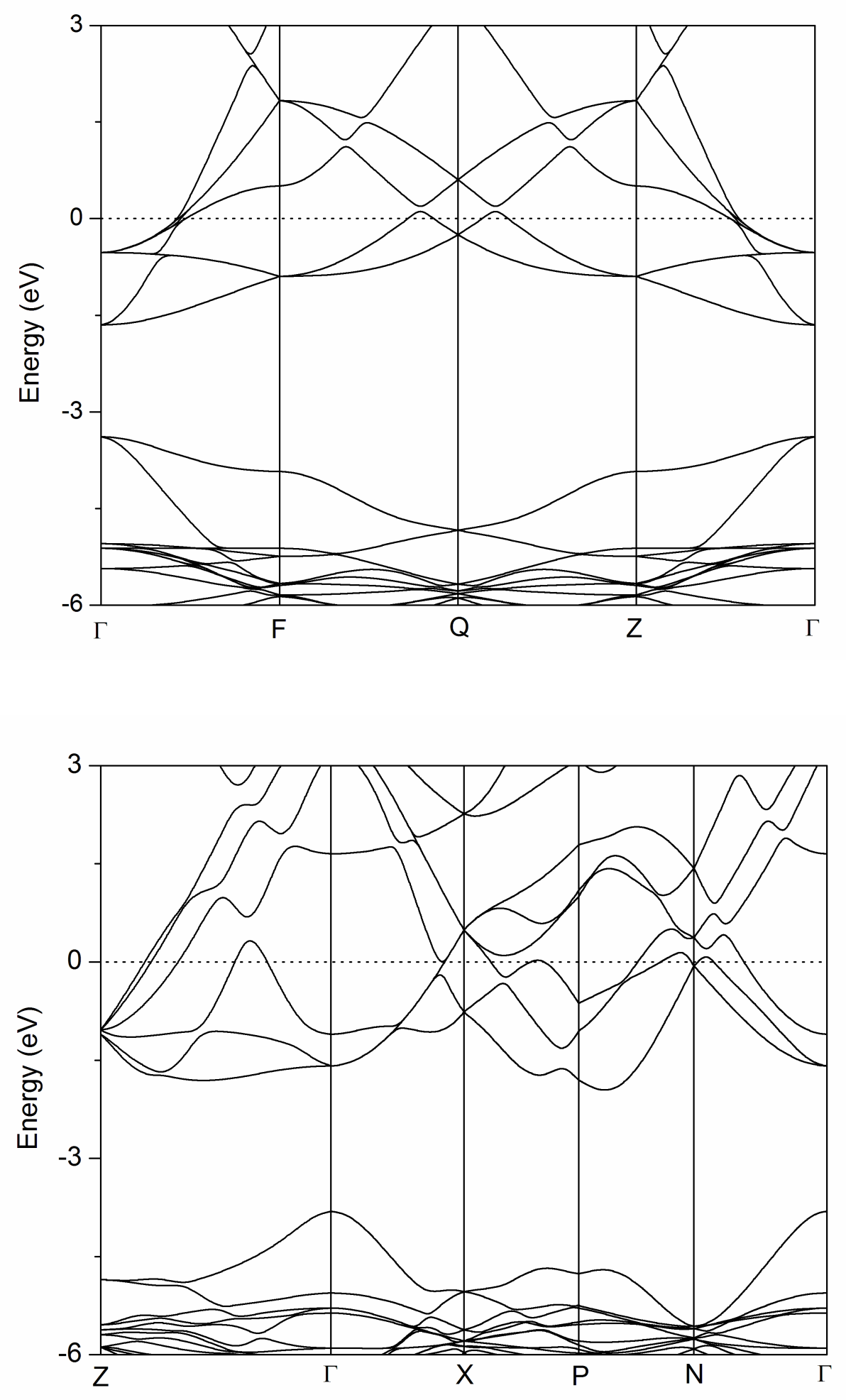


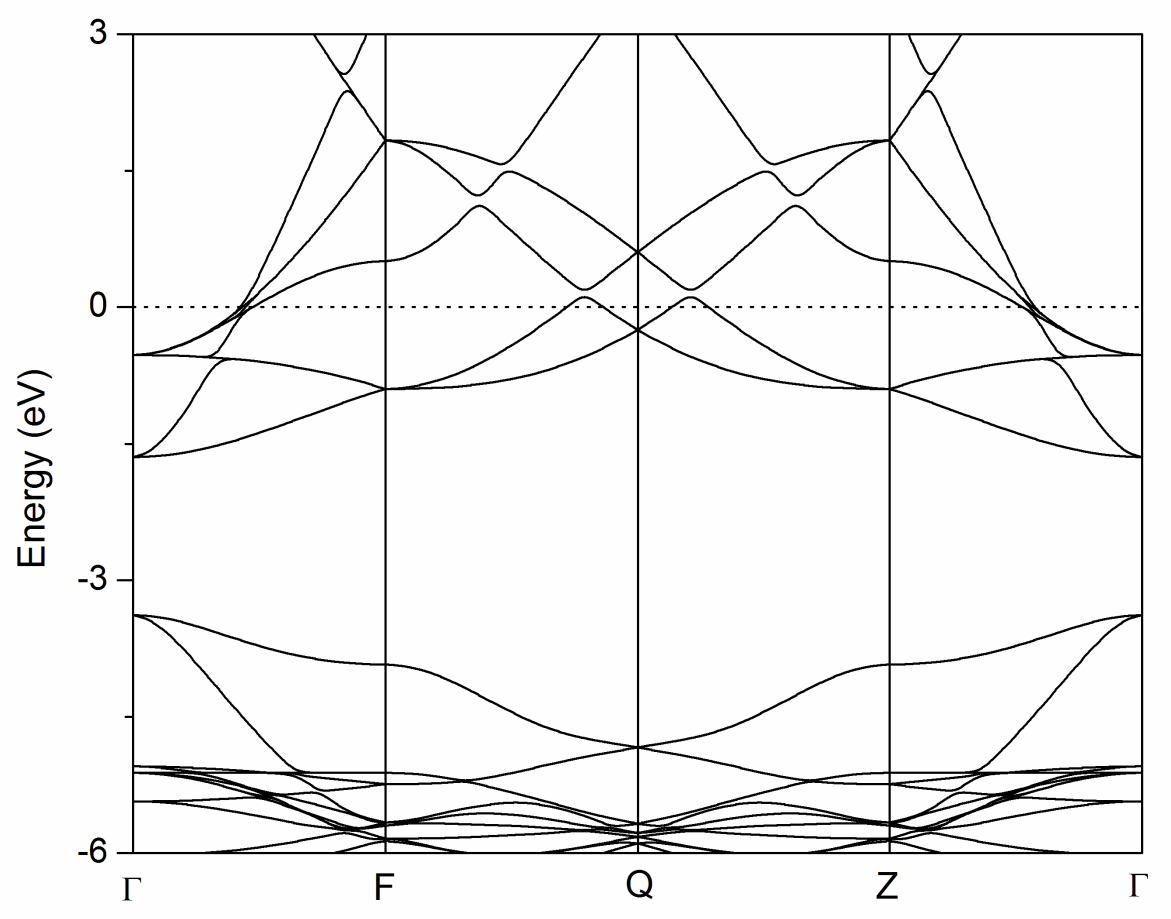

Figure S8. From top to bottom: electronic band structure of $\mathrm{Li}_{3} \mathrm{Au}$ in the $\mathrm{Fm}-3 m$ structure, $\mathrm{Li}_{4} \mathrm{Au}$ in the $I 4 / \mathrm{m}$ structure, and $\mathrm{Li}_{5} \mathrm{Au}$ in the $\mathrm{Cmmm}$ structure at $50 \mathrm{GPa}$. The dotted line indicates the Fermi energy.
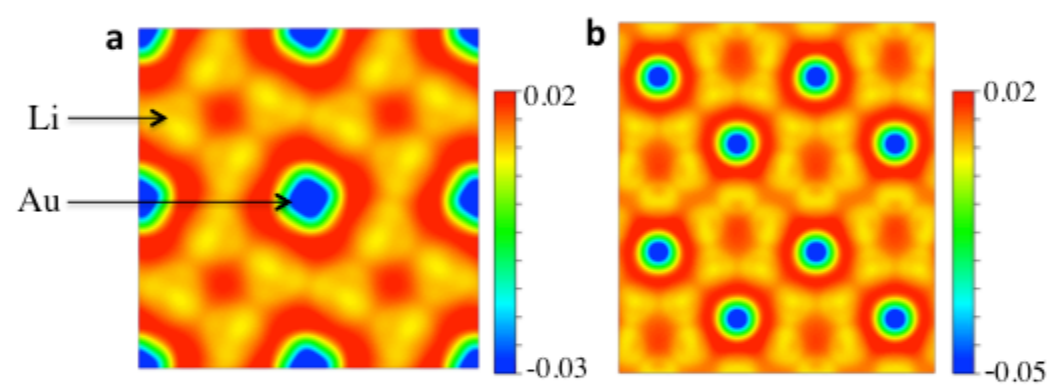

Figure S9. Difference charge density (crystal density minus superposition of isolated atomic densities) of $\mathrm{Li}_{4} \mathrm{Au}$ (a) plotted in the (001) plane and $\mathrm{Li}_{5} \mathrm{Au}$ (b) plotted in the (100) plane at $50 \mathrm{GPa}$. Arrows denote the positions of $\mathrm{Li}$ and $\mathrm{Au}$ atoms, as indicated. 


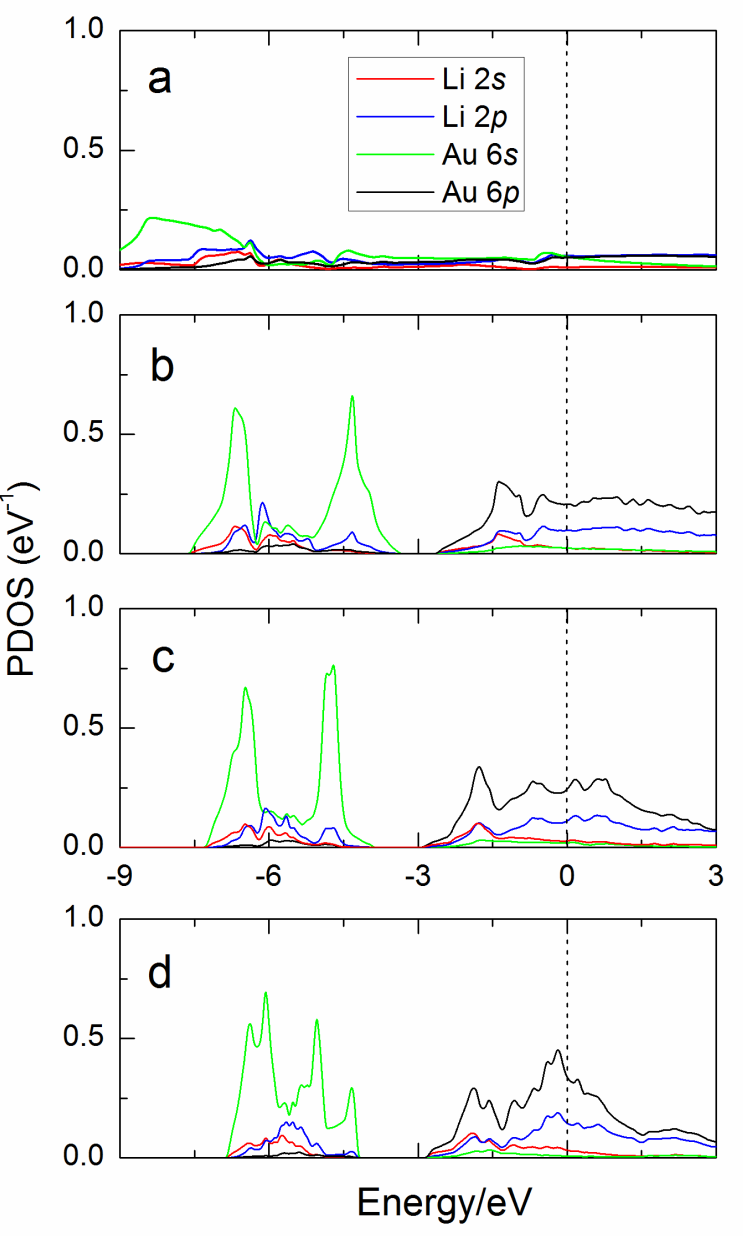

Figure S10. The calculated projected density of states per atom (PDOS) using the Perdew-Burke-Ernzerh functional for $\mathrm{LiAu}$ in the $\mathrm{CsCl}$ structure, $\mathrm{Li}_{3} \mathrm{Au}$ in the $F m-3 m$ structure, $\mathrm{Li}_{4} \mathrm{Au}$ in the $I 4 / m$ structure, and $\mathrm{Li}_{5} \mathrm{Au}$ in the $\mathrm{Cm} c m$ structure. The dashed line indicates the Fermi energy. Due to the $s$ to $p$ orbital hybridization, already observed for alkali metals under pressure, ${ }^{12}$ occupation of Li $2 p$ is much larger than $\mathrm{Li}$ $2 s$. PDOS around the Fermi level shows large occupations of Au $6 p$ as well as Li $2 p$, which are overlapped and favors the charge transfer from Li $2 p$ to Au $6 p$. 


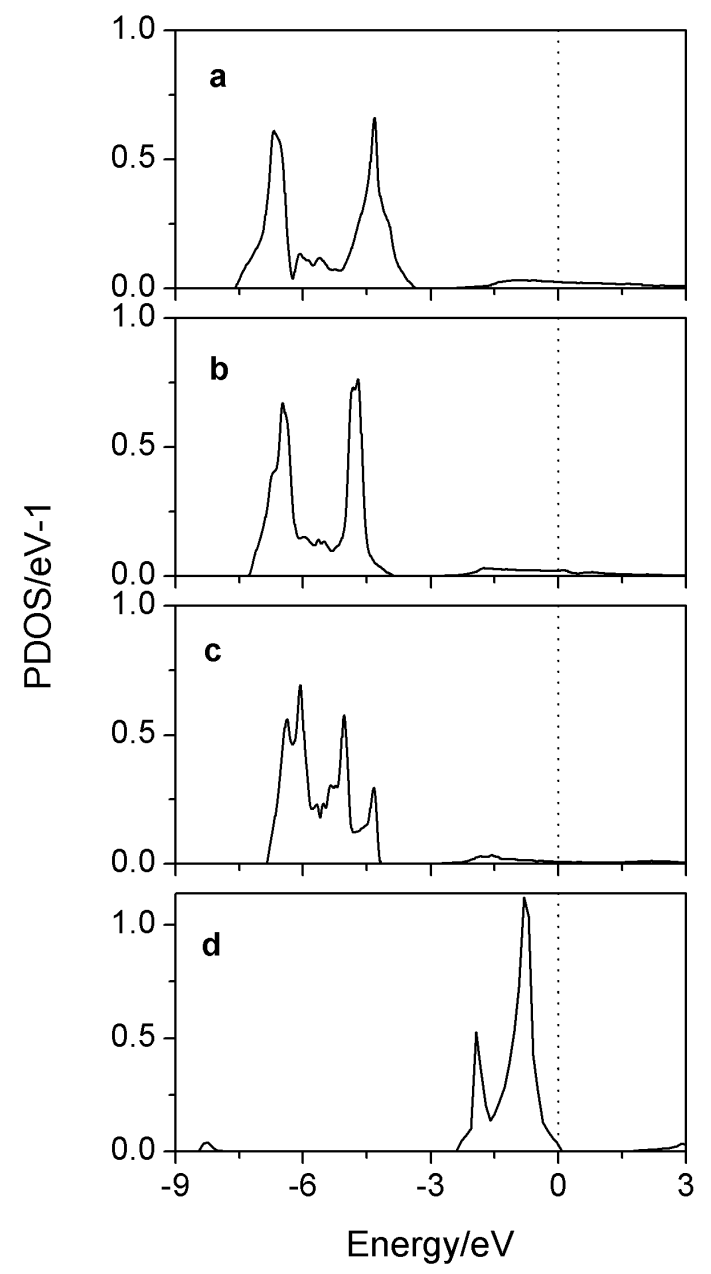

Figure S11. Comparison of projected density of states per atom (PDOS) of $\mathrm{Au} 6 s$ state for $\mathrm{Li}_{3} \mathrm{Au}$ in the $F m-3 m$ structure (a), $\mathrm{Li}_{4} \mathrm{Au}$ in the $I 4 / m$ structure (b), $\mathrm{Li}_{5} \mathrm{Au}$ in the $\mathrm{Cmcm}$ structure (c) at $50 \mathrm{GPa}$, and $\mathrm{CsAu}$ in the $\mathrm{CsCl}$ structure (d) at $0 \mathrm{GPa}$. The dotted line indicates the Fermi energy. In $\mathrm{CsAu}, \mathrm{Au}$ atom obtains one electron from $\mathrm{Cs}$ and shows $5 d^{10} 6 s^{2}$ electronic configuration. The integration of $\mathrm{Au} 6 s$ below the Fermi energy for $\mathrm{Li}_{3} \mathrm{Au} \mathrm{Li}_{4} \mathrm{Au}, \mathrm{Li}_{5} \mathrm{Au}$ and $\mathrm{CsAu}$ structures shows almost the same area, which indicates that $\mathrm{Au} 6 s$ orbitals in $\mathrm{Li}_{3} \mathrm{Au}, \mathrm{Li}_{4} \mathrm{Au}$ and $\mathrm{Li}_{5} \mathrm{Au}$ are fully filled. 


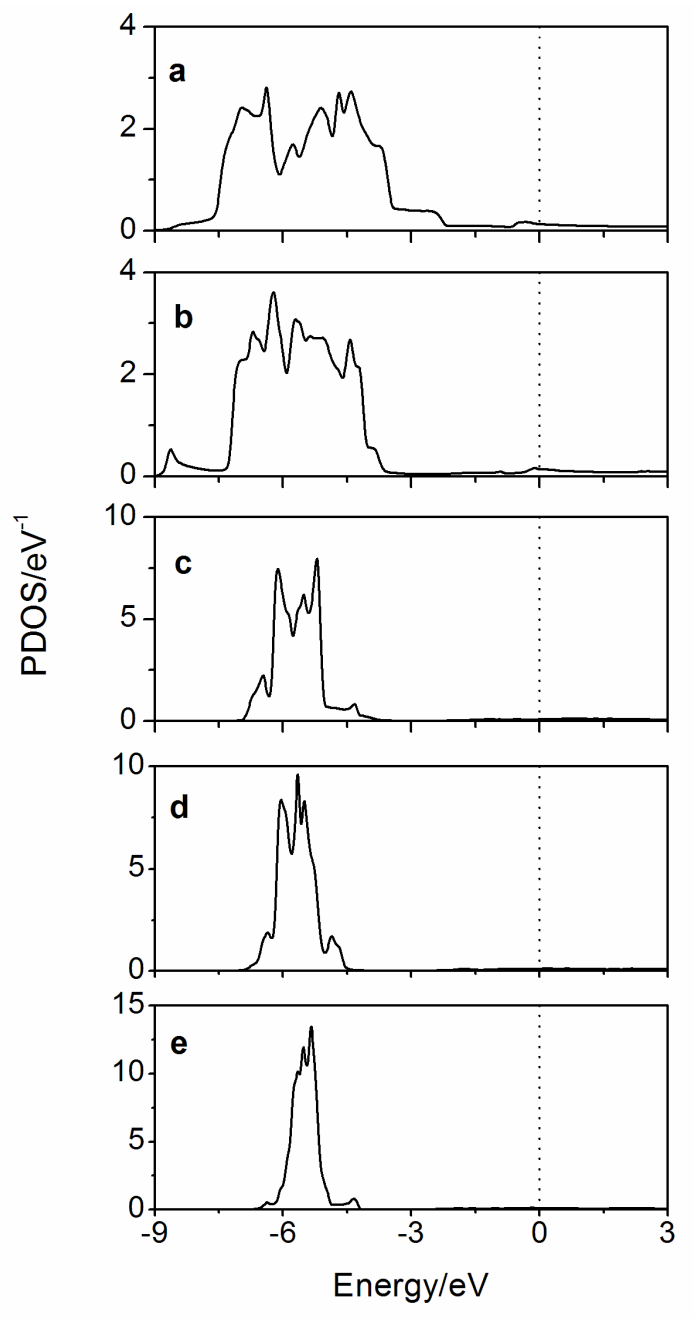

Figure S12. The projected density of states per atom (PDOS) of Au $5 d$ states of LiAu in $\mathrm{CsCl}$ structure (a), $\mathrm{Li}_{2} \mathrm{Au}$ in the $P 6 / \mathrm{mmm}$ structure (b), $\mathrm{Li}_{3} \mathrm{Au}$ in the $F m-3 m$ structure (c), $\mathrm{Li}_{4} \mathrm{Au}$ in the $I 4 / m$ structure (d), and $\mathrm{Li}_{5} \mathrm{Au}$ in the $C m m m$ structure (e) at $50 \mathrm{GPa}$. The dotted line represents the Fermi energy. Under pressure Au $5 d$ states are localized, which is enhanced increasing the Li content of the compound. The stronger dispersion of $\mathrm{Au} 5 d$ in $\mathrm{LiAu}$ and $\mathrm{Li}_{2} \mathrm{Au}$ might result from the shorter $\mathrm{Au}-\mathrm{Au}$ distances, 2.787 and $2.639 \AA$. 


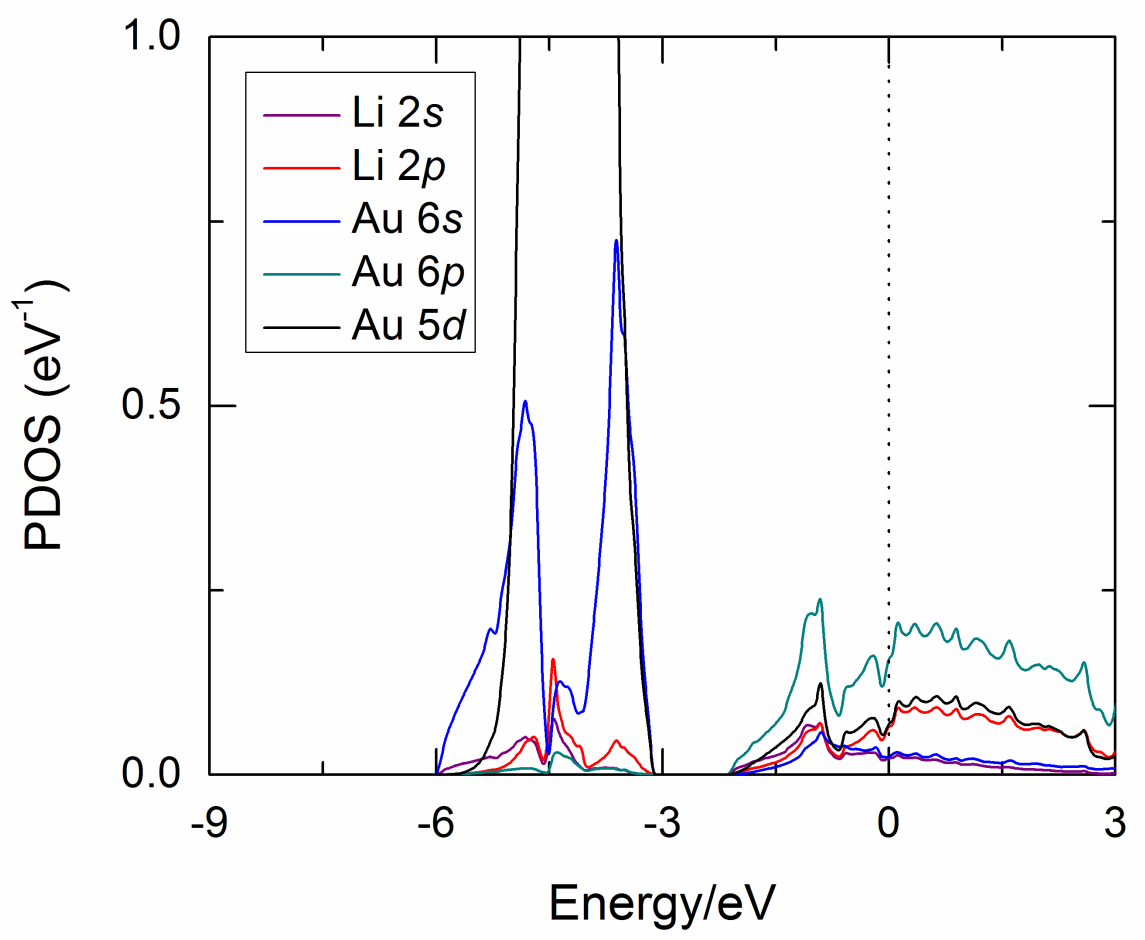

Figure S13 Calculated PDOS using the PBE functional for $\mathrm{Li}_{3} \mathrm{Au}$ in the $F m-3 m$ structure at $0 \mathrm{GPa}$. Although there appear Au $6 p$ electrons below the Fermi level, they are not coming from hydridization of $\mathrm{Li} 2 s$ and $2 p$ which have a small contribution. Thus, charge transfer character at high pressures is completely different from that at normal pressure. 


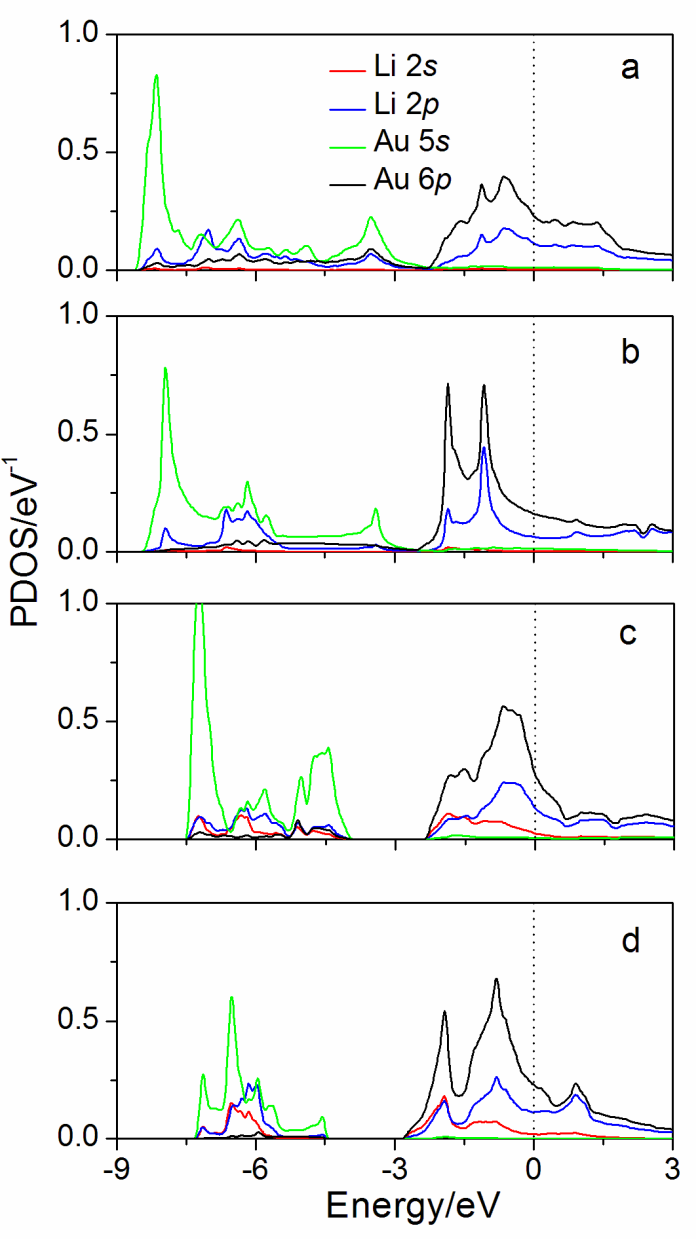

Figure S14. The projected density of states per atom (PDOS) of $\mathrm{Li}_{3} \mathrm{Au}$ in the $\mathrm{Cmcm}$ structure (a), $\mathrm{Li}_{4} \mathrm{Au}$ in the $I 4 / \mathrm{mmm}$ structure (b), $\mathrm{Li}_{5} \mathrm{Au}$ in the $C 2 / m$ structure (c), and $\mathrm{Li}_{6} \mathrm{Au}$ in the Imma structure (d) at $100 \mathrm{GPa}$. The dotted line represents the Fermi energy. It is found that the occupation of $\mathrm{Au} 6 p$ states is enhanced with increasing the $\mathrm{Li}$ content. Moreover, there also appears to be a strong overlap between $\mathrm{Li} 2 p$ and $\mathrm{Au}$ $6 p$, indicating that $\mathrm{Au}$ gains electrons from Li atoms. In comparison with the results at $50 \mathrm{GPa}$, increasing pressure can make Au atom gain more charge. 

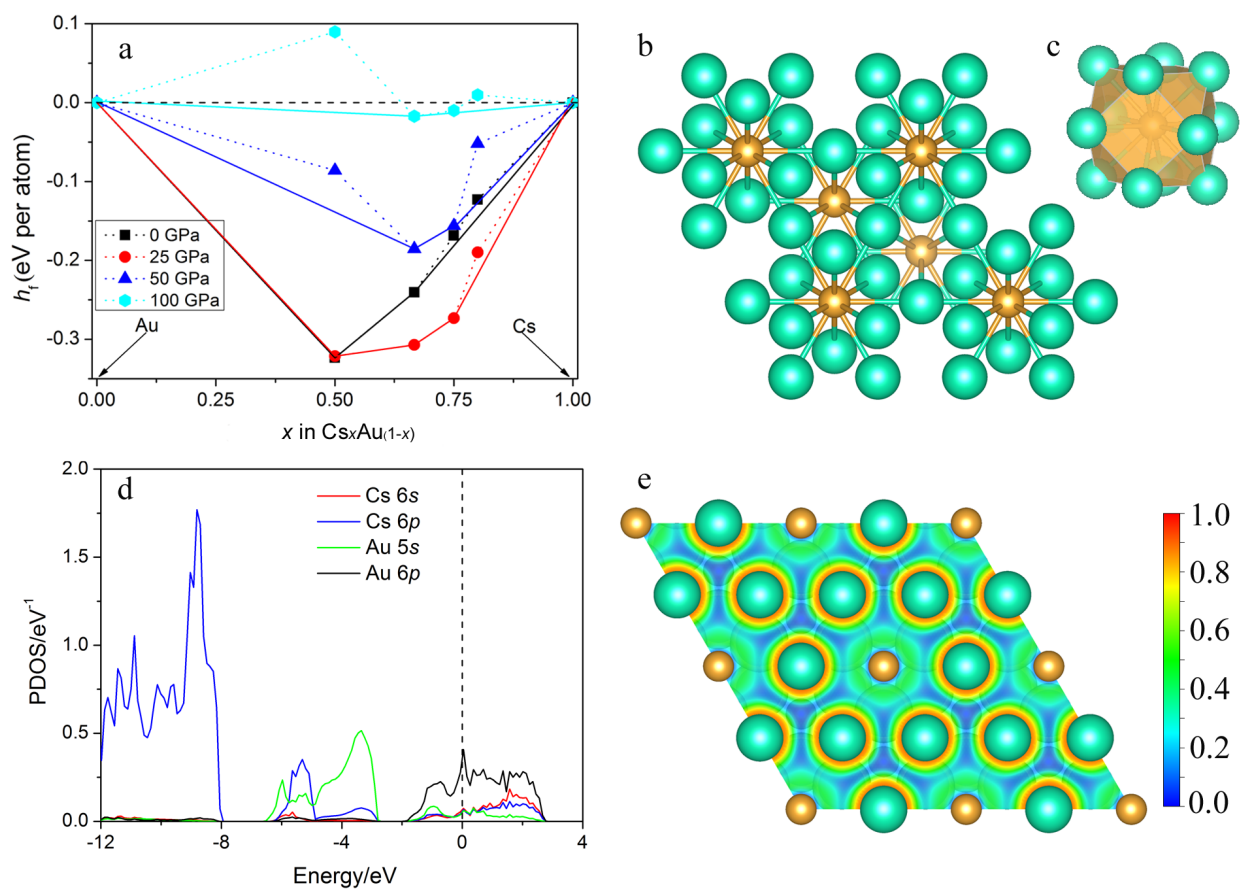

Figure S15. Main results for the Cs-Au systems (a-e). Structures of $\mathrm{Cs}_{n} \mathrm{Au}(n=1-4)$ compounds were investigated by the in-house developed CALYPSO structure prediction method. The convex hulls are shown by solid lines (Figure 15 a). Dotted lines that directly connect data points are guides for the eyes. Compounds corresponding to data points located on the convex hull are stable against decomposition. At ambient pressure, the experimental observation compound (CsAu with CsCl-type structure) was successfully reproduced. With increasing the pressure, Cs-rich compounds become stable $\left(\mathrm{Cs}_{2} \mathrm{Au}\right.$ and $\left.\mathrm{Cs}_{3} \mathrm{Au}\right)$, as found in $\mathrm{Li}-\mathrm{Au}$ systems. The Cs-rich compounds contain Au-centered polyhedrons, in which the $\mathrm{Au}-\mathrm{Au}$ distance is greatly larger than the aurophilic distance. For instance, $\mathrm{Cs}_{3} \mathrm{Au}$ has an hexagonal structure (space group $P 6_{3} / m m c, 2$ formula units per cell; Figure 15b) at 25 $\mathrm{GPa}$. Each $\mathrm{Au}$ is surrounded by twelve nearest neighboring Cs atoms with two different kinds of $\mathrm{Cs}^{-}-\mathrm{Au}$ distances, 3.06 and $3.13 \AA$. The shortest $\mathrm{Au}-\mathrm{Au}$ distance $(4.39 \AA)$ is much longer than the aurophilic distance $(3.0 \AA)$. Thus, the $\mathrm{Au}-\mathrm{Au}$ interaction in $\mathrm{Cs}_{3} \mathrm{Au}$ is rather weak. Figure $15 \mathrm{c}$ shows the view of a dodecahedral in $\mathrm{Cs}_{3} \mathrm{Au}$. The calculated projected density of states per atom (PDOS) of $\mathrm{Cs}_{3} \mathrm{Au}$ is shown in Figure 15d. A large charge transfer from the Cs $6 p$ to the $\mathrm{Au} 6 p$ occurs. The calculated electronic localization function 
for $\mathrm{Cs}_{3} \mathrm{Au}$ in the $\mathrm{Pb}_{3} / m m c$ structureat $25 \mathrm{GPa}$ on the (001) plane indicates that there are large areas between $\mathrm{Cs}$ and $\mathrm{Au}$ atoms with small ELF values. Thus, $\mathrm{Cs}-\mathrm{Au}$ bonding is mainly ionic and metallic.

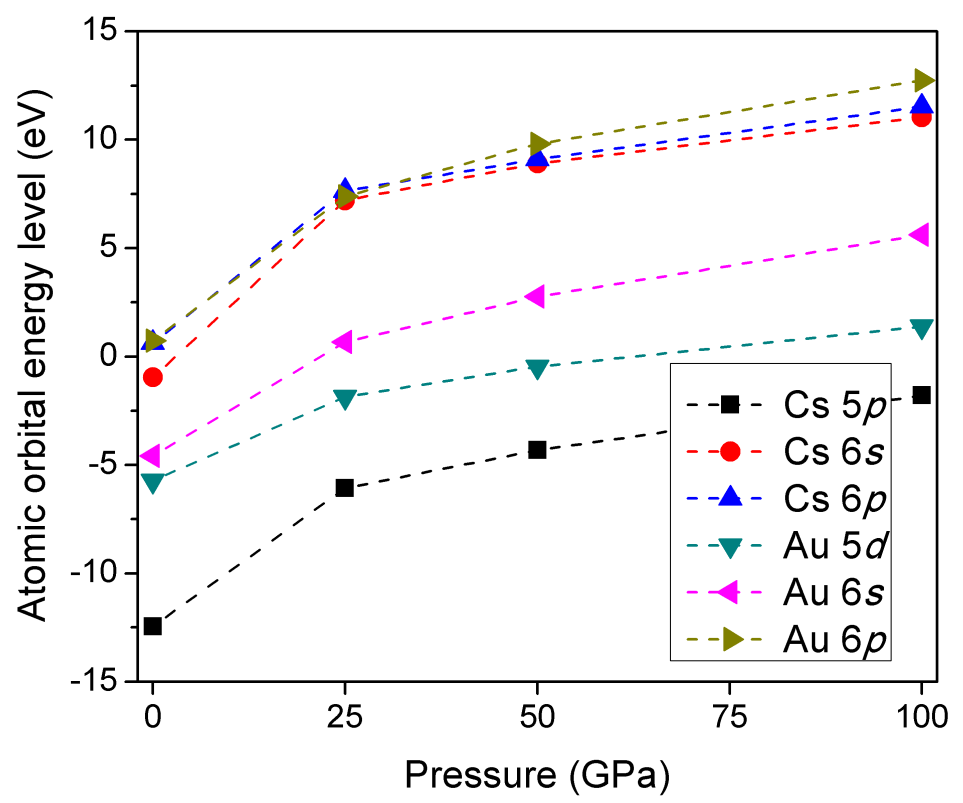

Figure S16. Atomic orbital energy levels for $\mathrm{Cs}$ and $\mathrm{Au}$ atoms as a function of the external pressure. Pressure effect is modeled by putting elements in a face-centered cubic (fcc) He matrix. A fcc supercell of $108 \mathrm{He}(3 \times 3 \times 3)$ is used, in which one $\mathrm{He}$ atom is replaced by the atom being examined. 


\section{Reference:}

(1) Wang, Y.; Lv, J.; Zhu, L.; Ma, Y. Phys. Rev. B 2010, 82, 094116.

(2) Wang, Y.; Lv, J.; Zhu, L.; Ma, Y. Comput. Phys. Commun. 2012, 183, 2063.

(3) Kresse, G.; Furthmuller, J. Phys. Rev. B 1996, 54, 11169.

(4) Perdew, J. P.; Chevary, J. A.; Vosko, S. H.; Jackson, K. A.; Pederson, M. R.;

Singh, D. J.; Fiolhais, C. Phys. Rev. B 1992, 46, 6671.

(5) Pelton, A. D. Bull. Alloy. Phase. Diagr. 1986, 7, 228.

(6) Dronskowski, R. \& Blochl, P. E. J. Phys. Chem. 1993, 97, 8617.

(7) Jepsen, O.; Aaronson, O. K. Z. Phys. B 1995, 97, 35.

(8) Derrien, G.; Monconduit, L.; Tillard, M.; Belin, C. Acta Crystallogr Sect C, 1999, $55,1044$.

(9) Togo, A.; Oba, F.; Tanaka, I. Phys. Rev. B 2008, 78, 134106.

(10) Errea, I.; Calandra, M.; Pickard, C. J.; Nelson, J.; Needs, R. J.; Li, Y. W.; Liu, H. Y.; Zhang, Y. W.; Ma, Y. M.; Mauri, F. Phys. Rev. Lett. 2015, 114, 157004.

(11) Botana, J.; Miao, M. S. Nat. Commun. 2014, 5, 4861.

(12) Christensen, N. E. \& Novikov, D. L. Solid. State. Commun. 2001, 119, 477. 